\title{
Regional Networks in Acute Cardiac Care
}

\author{
Monica Marton-Popovici \\ Swedish Medical Center, Department of Internal Medicine and Critical Care, Edmonds, Washington, USA
}

\section{ABSTRACT}

In acute cardiac care, the timely initiation of life-saving measures proved to be life-saving and requires many organizational and logistic measures. One of such measures is represented by the development and implementation of a regional network dedicated for the treatment of major cardiovascular emergencies, a strategy that proved to significantly reduce mortality rates on short and long term. This review aims to describe the current status in the development of regional networks in three of the main cardiovascular emergencies: acute myocardial infarction, out-of-hospital cardiac arrest, and acute stroke. The concepts demonstrating the utility of such networks, together with their results in reducing cardiac events, are presented in this paper.

Keywords: acute myocardial infarction, acute stroke, out-of-hospital cardiac arrest, network, mortality

\section{ARTICLE HISTORY}

Received: August 19, 2017

Accepted: September 20, 2017

\section{CORRESPONDENCE}

Monica Marton-Popovici

Swedish Medical Center

Department of Internal Medicine and Critical Care

21601, 76th Ave W, Edmonds,

Washington, 98026, USA

E-mail: monica.marton-popovici@

swedish.org
Cardiovascular diseases continue to represent a group of devastating diseases, and proper treatment of cardiovascular emergencies is one of the key factors required to reduce cardiovascular mortality. ${ }^{1}$ In acute cardiac care, the timely initiation of life-saving measures requires many organizational and logistic measures., ${ }^{2,3}$ One of such measures is represented by the development and implementation of a regional network dedicated for the treatment of major cardiovascular emergencies, a strategy that proved to significantly reduce mortality rates on short and long term. 4,5 This review aims to present the current applications of regional networks in three of the main cardiovascular emergencies: acute myocardial infarction, out-of-hospital cardiac arrest (OHCA), and acute stroke.

\section{STEMI NETWORKS}

The implementation of dedicated networks for urgent revascularization in patients with ST-elevation myocardial infarction (STEMI) have been proved to represent a life- saving strategy and is currently the goal of many health-

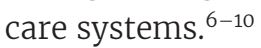

In patients with acute myocardial infarction, survival depends largely on the amount of viable myocardium remaining after the infarction..$^{11-13}$ The recovery of myocardial tissue is the main goal of therapy in emergency settings and can be achieved by urgent revascularization..$^{14-16}$

In order to be effective, reperfusion of an occluded coronary artery should be achieved in the first 12 hours after the onset of chest pain. ${ }^{17}$ While many precious hours are lost by the patients who do not present in time to the specialized services, sustained organizational efforts have been made in order to shorten the time from presentation to revascularization. ${ }^{18-22}$

One of the first regional STEMI networks has been initiated in the USA in Minnesota, including referral hospitals located at a radius of 210 miles from the pPCI center. The geographic territory surrounding the PPCI center was divided in 2 zones according to their distance to the pPCI center, and the treatment strategy (pPCI or pharmacoinvasive) was individualized according to each zone, in 
relation to the transfer time. This complex model proved to increase the access of STEMI patients to coronary permeabilization and served as model for other STEMI networks. ${ }^{23}$

In a study published 3 years ago, Benedek et al. proved that implementation of a regional network for STEMI treatment in a population of 1 million inhabitants was able to reduce STEMI-related mortality from $20.73 \%$ to $6.35 \%$ within 5 years, in parallel to increasing the rate of primary percutaneous interventions from $10.8 \%$ to $78.6 \%{ }^{24}$ At the same time, another study showed that a well-organized STEMI network can significantly reduce the network times (time from the presentation to STEMI protocol initiation and the door-to-balloon time) and is able to achieve better outcomes in terms of survival even in centers located at long distance from a pPCI center. ${ }^{25}$ Interestingly, government-based implementation of interventional treatment in STEMI was more successful in those territories with pre-existing such networks, where the network-based logistics were already in place and the STEMI-specific algorithms were already familiar to the physicians. ${ }^{26}$

A similar network implemented in Spain demonstrated to reduce in-hospital mortality from $7.1 \%$ prior to network to $2.5 \%$ post network. ${ }^{27}$ Another Spanish study showed a significant reduction in STEMI-related in-hospital mortality from $10.2 \%$ in 2003 to $6.8 \%$ in 2012 following development and implementation of a regional network for STEMI treatment. ${ }^{28}$

The Vienna STEMI network included the ambulance service and 6 pPCI centers providing 24/7 STEMI interventional treatment. ${ }^{29}$ Analysis of the data collected in the Vienna STEMI registry, using Vienna STEMI network, showed that in very well-structured STEMI networks, such as the one in Vienna, there are no significant differences in terms of mortality between patients treated "onhours" and those treated "off-hours". ${ }^{29}$

Significant efforts should be addressed to increase the adherence rates for these life-saving strategies in STEMI patients. In an Acute Coronary Syndromes Registry in Jakarta published last year, $46 \%$ of STEMI patients received no reperfusion and these regions from developing countries could significantly benefit from such networks. ${ }^{30}$

However, one of the main shortcomings of a systembased protocol initiation in a STEMI network is represented by the possible false STEMI alerts. Network activation at the first contact, by a non-specialist practitioner, has been proved to reduce the delay times but with the cost of a large number of false STEMI alarms. In a study of Regueiro et al. on over 5,000 STEMI activa- tions, the rate of false clinical positives was as high as $11.6 \% .^{31}$

An important issue in STEMI networks is related to the transfer of patients with high-risk STEMI. In an analysis including 119,680 STEMI patients out of which 37,028 were transferred between hospitals and 4,500 of them were high-risk, in-hospital mortality rates were not significantly higher in patients accepting high-risk transfer STEMI patients, indicating that high-risk patients should be transferred as soon as possible to well-equipped and experienced centers. ${ }^{32}$

As a significant proportion of STEMI patients (approximately 50\%) present to hospitals without PCI facilities, adjunctive methods have been proposed in order to ensure a fast diagnosis and get the patient as soon as possible to the cath lab. One of these measures is represented by smartphone-based networking system, which seems to reduce the total ischemic time based on a more rapid communication and more rapid diagnosis. ${ }^{33}$

\section{NETWORKS FOR OUT-OF- HOSPITAL CARDIAC ARREST}

In patients with OHCA, the implementation of regional models similar to those used in STEMI networks has been proposed in an attempt to decrease the OHCA-related mortality. ${ }^{34-36}$

The neurological outcomes and the chance of survival could be considerably increased by implementing new therapeutic management options. ${ }^{37,38}$ A systematic approach of subjects that present OHCA, by applying therapeutic hypothermia if the patient is comatose, extra-corporeal cardio-pulmonary resuscitation (ECPR) methods, emergency invasive coronary angiography, and advanced life support measures in pre-hospital setting, have been shown to significantly increase the neurological status and discharge rates for these patients. Hwang et al. aimed to identify the effect of such a systematic approach on 581 adult patients with OHCA, and their results showed an increase in the rate of discharge with an improved neurological status from 3.3\% to $8.5 \%$ over a period of 5 years (from 2009 to 2013). ${ }^{39}$

Data from a prospective registry of non-traumatic OHCA in adult subjects showed that the initiation of ECPR within a 16-minute time frame had the highest sensitivity and specificity for predicting survival (AUC $=0.87,95 \%$ CI: $0.85-0.89$ ). The study, which included 1,206 cases with a $27 \%$ overall survival rate, found that patients with shockable rhythms had a survival rate of $31 \%$ if CPR was initiated within the first 8 minutes and $10 \%$ if it was ini- 
tiated in the first 24 minutes. In case of non-shockable rhythms, the probability of survival was $5.2 \%$ and $1.6 \%$ if the subjects were resuscitated in the first 8 minutes and 24 minutes respectively..$^{40}$

Spangerberg et al. aimed to identify the feasibility and outcomes of patients who underwent ECPR, and their results revealed a significant association between survival rates and initiation of bystander CPR ( $p=0.03)$, as well as a significantly lower period of time until initiation of ECPR measures in these patients $(p=0.004) .{ }^{41}$ On the other hand, an increased duration from conventional resuscitation measures to initiation of EPCR leads to impaired survival of OHCA patients. ${ }^{42}$

The Canadian registry of non-traumatic OHCA aimed to integrate a methodology based on initiation of ECPR in an already existing high-performance system, which presented a significant impact on outcomes and discharge rates. From $68 \%$ of patients who survived the OHCA for admission, $42 \%$ were discharged alive. 43

Ha et al. analyzed the in-hospital mortality rates of 35 patients with OHCA, in relation to ECMO initiation, the time from arrest to $\mathrm{CPR}$, the presence of ischemic etiology, and coronary revascularization. The study did not find any significant differences between subjects who had died and those who survived regarding the mean time from arrest to CPR (survivors - 23.5 minutes vs. deceased - 20.0 minutes, $\mathrm{p}=0.41$ ) or the time from CPR to ECMO (survivors -61.0 minutes vs. deceased -50.0 minutes, $p=0.50$ ). However, the number of patients who underwent coronary revascularization was significantly higher in the survivor group compared to the non-survivor group (80.0\% vs. $32.0 \%$ respectively, $\mathrm{p}=0.02$ ). The multivariate Cox regression analysis found that witnessed arrest, bystander $\mathrm{CPR}$, and a successful coronary revascularization were independent predictors for in-hospital survival rates. ${ }^{44}$

A retrospective analysis on 195 patients with resuscitated OHCA who survived upon hospital admission in the Maastricht region of the Netherlands, after implementing ECPR methods, found significant differences between survivors and non-survivors regarding age (63 vs. 70 years, $p$ $=0.01)$, chronic heart failure ( $7 \%$ vs. $18 \%, p=0.02)$, shockable rhythms ( $99 \%$ vs. $67 \%, \mathrm{p}<0.01$ ), and return to spontaneous circulation (ROSC) in pre-hospital settings ( $99 \%$ vs. $46 \%, \mathrm{p}<0.01)$. Moreover, coronary revascularization was performed in $52 \%$ of cases in the survivor group and in only $14 \%$ of cases in the deceased group ( $\mathrm{p}<0.01)$. The overall survival rate during hospitalization was $46.2 \%$, and no statistical significance was observed between the two groups in relation to gender, witnessed arrest, bystander CPR, or the use of automated external defibrillators (AED). 45
Another study on an Italian population that included 1,128 OHCA patients showed that there was a significant improvement in the survival of these patients (from 5.6\% to $13.01 \%$ from 2007 to 2011 ) after implementing a new bundle of care that included the use of AED, therapeutic hypothermia, and ECPR. The most significant factor associated with higher survival was found to be bystander CPR and dispatch-assisted CPR in the studied cohort. ${ }^{46}$

Comparable to STEMI network times, such as "doorto-needle" and "door-to-balloon" times, which are utilized in analyzing the efficiency and efficacy of a systembased approach in the management of acute myocardial infarction, the cardiac arrest networks include the "doorto-implantation" of ECMO time in the cath lab. Leick et al. studied the characteristics and outcomes of patients with OHCA who underwent ECMO during PCI and found that the "door-to-ECLS" time was significantly longer in non-survivors ( 42.5 minutes vs. 25.0 minutes, p <0.01), the duration of ECLS did not differ between survivors and deceased (survivors -4.0 days, deceased -6.5 days, $\mathrm{p}=0.69$ ), but a door-to-implantation time of less than 30 minutes was an independent predictor for the 30-day outcome in patients with OHCA. ${ }^{47}$

\section{STROKE NETWORKS}

One of the most promising applications of medical networking is represented by the possibility to develop networks for the treatment of acute stroke. ${ }^{4-50}$

Acute ischemic stroke is responsible for approximately $85 \%$ of acute strokes, and in $30-40 \%$ of these cases (those caused by occlusion of a large vessel), a catheter-based intervention is possible. ${ }^{51}$ Similar to the experience encountered in STEMI treatment, a shorter time from the onset of stroke to intervention is associated with a significant improvement in survival rates and amelioration of the neurologic deficit. In acute ischemic stroke, a timely reperfusion can lead to preservation of viable cerebral tissue (Widimski EHJ), in a similar fashion with the wellknown functional recovery of viable myocardium after the timely opening of an occluded coronary vessel. However, in the case of stroke patients, the time interval from onset to reperfusion is set to a lower limit, reperfusion being indicated within the first 3 hours after the onset of stroke. ${ }^{51}$

Taking into consideration this significant limitation represented by a short time window in which reperfusion is indicated, dedicated telenetworks for emergency treatment of acute ischemic stroke have been developed in recent years, showing superior results in terms of reducing mortality and dependency. ${ }^{52-54}$ 


\section{STRATEGIES TO MINIMIZE THE CRITICAL TIMES IN STROKE}

Other strategies addressed to minimize the time to treatment in ischemic stroke include bypassing the emergency room and direct transfer to the cath lab, dedicated ambulances equipped with mobile CT or MRI in order to facilitate the initiation of thrombolysis already in the ambulance, or the so-called "double alert system", meaning a first alert transmitted to the cath lab whenever a potential stroke has been identified, followed by a second alert after the stroke has been confirmed by imaging. ${ }^{51} \mathrm{~A}$ long time from stroke onset to reperfusion, as the one of $5.5 \mathrm{~h} \mathrm{re-}$ corded in the MR CLEAN trial, was associated with a high mortality of $18.9 \%$, while a time of $4.1 \mathrm{~h}$ in the EXTENDIA trial was associated with a significantly lower mortality, of 8.6\%.55,56 Similarly, a time of 355 minutes in the REVASCAT trial was associated with a mortality of $18.4 \%$ at 90 days, while a time of 241 minutes led to a mortality of $10.4 \%$ in the ESCAPE trial, and a time of 248 minutes in the SWIFT PRIME trial associated a mortality of $9.2 \% .{ }^{57-59}$

\section{DIRECT CATHETER-BASED REPERFUSION IN STROKE AND CARDIOLOGY-BASED NETWORKS}

Direct catheter-based reperfusion without thrombolysis has been proposed as a valid therapy for ischemic stroke starting with 2001. ${ }^{60}$ At the beginning, this procedure was performed only by neuroradiologists and neurosurgeons; however, starting with 2008 , it also became to be applied by interventional cardiologists skilled in emergency treatment of STEMI patients. ${ }^{61}$ Interventional cardiology teams have already implemented 24/7 networks and logistics for the treatment of acute STEMI, and these facilities can be easily made available for the interventional treatment of ischemic stroke. Furthermore, interventional cardiology services have an interventional team available in the hospital for treating STEMI anyway, which is usually not the case for neurologists or interventional radiologists. ${ }^{62-65}$ At the same time, interventional cardiologists are very skilled in cardiovascular interventions, and usually they are well experienced with network-based treatment strategies, after implementing and working in well-functioning STEMI networks which could be easily extrapolated to stroke networks. ${ }^{66,67}$

The PRAGUE-16 trial aimed to assess the role of catheter-based thrombectomy in acute ischemic stroke and the feasibility of this method when performed by interventional cardiology teams. This trial succeeded to demonstrate that acute stroke interventions performed by teams formed by interventional cardiologists, neurologists, and radiologists are feasible and safe, and showed that the involvement of a cardiology team in acute stroke interventions could be indicated especially in hospitals where an emergency neurointerventional radiology service is not available. $^{68}$

Bridging thrombolysis represents the administration of intravenous thrombolysis as a bridge to the mechanicalbased reperfusion. The ESCAPE trial failed to demonstrate, in its subgroup analysis, any significant difference in the rate of recanalization in patients who received intravenous bridging thrombolysis as compared to those who received direct catheter-based thrombectomy without prior thrombolysis.59 Currently, thrombectomy represents a class IA indication for patients with acute ischemic stroke presenting in the first 6 hours after the onset of stroke. ${ }^{59}$

The STRATIS registry, including 984 patients with stroke treated in 55 centers, showed that interhospital transfer is associated with worse outcomes and delay in treatment initiation in stroke patients. In the direct group, $60.0 \%$ of patients achieved functional independence compared to $52.2 \%$ in the transfer group ( $p=0.02)$, and a modified Rankin score of $0-1$ was recorded in $47.4 \%$ of patients treated directly as compared to $38.0 \%$ in those transferred, however, without a significant difference in mortality. ${ }^{69,70}$

\section{TELESTROKE NETWORKS}

Due to the lack of sufficient number of stroke specialists especially in centers located at a large distance to a stroke unit, many hospitals initiate thrombolysis based on a remote consultation with specialists located in a hub, using telemedicine facilities. The networks developed around a central hub using telemedicine-based communication in order to facilitate rapid initiation of thrombolytic treatment in stroke have been named stroke telenetworks. ${ }^{71-74}$

Stroke telenetworks have been shown to significantly reduce the time intervals from stroke onset to successful reperfusion and could represent a promising solution for reducing the critical times from stroke to reperfusion. ${ }^{75} \mathrm{~A}$ study published recently on 542 stroke patients treated in a telestroke network in East Saxony showed the superiority of a telenetwork approach for intravenous thrombolysis, especially in young patients. Time was proved to represent a critical issue for favorable outcomes, especially in elderly stroke patients. ${ }^{76}$

In another study on a large telestroke cohort in the Delaware valley, the differences between patients transferred and non-transferred to a primary stroke care center 
have been evaluated. The network consisted in a central hub and 29 spoke hospitals dealing with acute stroke patients. The results of this study indicate a linear decline in the rate of transfers to a primary care stroke center over 3 years, with only $12 \%$ of patients being transferred. ${ }^{77}$ Another study published two years ago also demonstrated that telemedicine can improve the results of stroke treatment in a hospital network in expansion. ${ }^{78}$

In a recent meta-analysis including 7 studies on 1,863 patients, Kepplinger et al. demonstrated that whenever accomplished in the first 3 hours after the onset of stroke, intravenous thrombolysis using the guidance of a stroke telenetwork is safe and effective. In this meta-analysis, no significant differences in mortality or functional independence at 3 months were recorded between the telemedicine-guided group and the group treated in the stroke center, showing that stroke telenetworks could represent a viable tool for the treatment of ischemic stroke, especially in cases located at a long distance to the stroke center. $^{79}$

The strategy consisting in the initiation of thrombolytic treatment in a spoke hospital under the guidance provided by a specialist located in a central hospital using telemedicine facilities, followed by the transfer of patient to the central hospital, has been named the "drip and ship" strategy and proved to provide outcomes comparable to those obtained using treatment directly in the central hospital. ${ }^{80}$ In addition, a study by Heffner et al. analyzed the difference in terms of outcomes between the patients sent to the central hub and those remaining in the spoke hospitals after thrombolysis (the "drip and ship" versus "drip and stay" strategy). They found that despite having less severe stroke and a lower incidence of major vessel occlusion, patients in the drip-and-stay strategy arm presented a significantly increased risk of adjusted in-hospital mortality (OR 13.2, 95\% CI 3.5-50.2) and decreased long-term survival rates as compared to patients transferred to the hub hospital $(\mathrm{p}<0.0001) .{ }^{81}$

In a retrospective study that investigated the effectiveness of the stroke pathways and trends over time in a stroke telenetwork in the Veneto region, Nardatto et al. demonstrated that the implementation of such a huband-spoke-based telenetwork increases the proportion of admissions in a stroke unit and is directly related with a lower mortality and an increased percentage of patients who received timely reperfusion. At the same time, this study indicates that the implementation of several centers of excellence highly specialized in stroke treatment can represent an effective strategy for reducing strokerelated mortality. ${ }^{82}$ The same conclusion has been reached by Chalouhi et al., who showed that implementing a telestroke system facility based on telemedicine consultations delivered through remote-presence robotic technology leads to a significant increase in the rate of intravenous thrombolysis, $82 \%$ of the hospitals included in the network reporting an increase in the thrombolytic use during the study period. ${ }^{83}$

In a very recent publication, Klinger et al. addressed the issue of the decision to transfer the patient within a telestroke network and showed that patient age and the location of the occlusion in one major vessel were the key determinants for the decision to transfer the patient. Interestingly, the time from the symptoms onset to the moment of decision did not play a significant role in the decision process in this study. ${ }^{84}$

In a study on 164 telestroke patients thrombolyzed using telemedicine facilities, Ranta et al. demonstrated that the implementation of a telestroke network is associated with a significant increase in the rate of timely initiation of intravenous thrombolysis and a significant reduction in door-to-needle time, represented by the time from patient presentation to the moment of thrombolysis initiation. Interestingly, this study also showed a significant benefit resulting from the more rapid virtual interaction between the patient and the doctor in the hub hospitals in the out-of-hours period. ${ }^{85}$

All these data underline the role of modern networking, including telemedicine-based networking, for decreasing critical time delays and improving outcomes in treatment of acute stroke.

\section{CONCLUSION}

Modern networks dedicated to acute cardiac care proved to be life-saving in both acute myocardial infarction and acute stroke. The extension of such networks in complex regional logistic models dedicated to improve the survival after out-of-hospital cardiac arrest is recommendable and achievable.

\section{CONFLICT OF INTEREST}

Nothing to declare.

\section{REFERENCES}

1. Cardiovascular diseases (CVDs). Available at: http://www.who. int/mediacentre/factsheets/fs317/en/

2. Measuring and Improving Quality of Care A Report From the American Heart Association/American College of Cardiology First Scientific Forum on Assessment of Healthcare Quality in 
Cardiovascular Disease and Stroke. Circulation. 2000;101:14831493. https://doi.org/10.1161/01.CIR.101.12.1483.

3. Kreatsoulas C, Anand SS. The impact of social determinants on cardiovascular disease. The Canadian Journal of Cardiology. 2010;26:8C-13C.

4. Kozinski M, Pstragowski K, Kubica JM, et al. ACS networkbased implementation of therapeutic hypothermia for the treatment of comatose out-of-hospital cardiac arrest survivors improves clinical outcomes: the first European experience. Scand J Trauma Resusc Emerg Med. 2013;21:22. doi:10.1186/1757-7241-21-22.

5. Tubaro M, Danchin N, Goldstein P, et al. Pre-hospital treatment of STEMI patients. A scientific statement of the Working Group Acute Cardiac Care of the European Society of Cardiology. Acute Card Care. 2011;13:56-67. doi: 10.3109/17482941.2011.581292.

6. Rizzello V, Lucci D, Maggioni AP, et al. Clinical epidemiology, management and outcome of acute coronary syndromes in the Italian network on acute coronary syndromes (INACS Outcome study). Acute Card Care. 2012;14:71-80. doi: 10.3109/17482941.2012.655296.

7. Scholz KH, von Knobelsdorff G, Ahlersmann D, et al. Optimizing systems of care for patients with acute myocardial infarction. STEMI networks, telemetry ECG, and standardized quality improvement with systematic data feedback. Herz. 2008;33:102-109. doi: 10.1007/s00059-008-3120-6.

8. Claeys MJ, Sinnaeve PR, Convens C, et al. STEMI mortality in community hospitals versus PCI-capable hospitals: results from a nationwide STEMI network programme. Eur Heart J Acute Cardiovasc Care. 2012;1:40-47. doi:10.1177/2048872612441579.

9. Rokos I, Henry T, Weittenhiller B, et al. Mission: Lifeline STEMI Networks Geospatial Information Systems (GIS) Maps. Crit Pathw Cardiol. 2013;13:43-44. doi:10.1097/ HPC.ob013e31828cfe1b.

10. Bagai A, Al-Khalidi HR, Sherwood M, et al. Regional systems of care demonstration project: Mission: Lifeline STEMI Systems Accelerator: Design and methodology. Am Heart J. 2014;167:15-21. doi:10.1016/j.ahj.2013.10.005.

11. Masci PG, Bogaert J. Post myocardial infarction of the left ventricle: the course ahead seen by cardiac MRI. Cardiovasc Diagn Ther. 2012;2:113-127. doi:10.3978/j.issn.22233652.2012.04.06.

12. Bonow RO, Maurer G, Lee KL, et al. Myocardial Viability and Survival in Ischemic Left Ventricular Dysfunction. N Engl J Med. 2011;364:1617-1625. doi:10.1056/NEJMoa1100358.

13. Bonow RO, Castelvecchio S, Panza JA, et al. Ischemic Left Ventricular Dysfunction: Severity of Remodeling, Myocardial Viability and Survival After Surgical Revascularization. JACC Cardiovasc Imaging. 2015;8:1121-1129. doi:10.1016/j. jcmg.2015.03.013.

14. Montalescot G, Andersen HR, Antoniucci D, et al. Recommendations on percutaneous coronary intervention for the reperfusion of acute ST elevation myocardial infarction. Heart. 2004;90:e37.

15. Windecker S, Kohl P, Alfonso F, et al. The Task Force on Myocardial Revascularization of the European Society of Cardiology (ESC) and the European Association for CardioThoracic Surgery (EACTS) Developed with the special contribution of the European Association of Percutaneous Cardiovascular Interventions (EAPCI). Eur Heart J.
2014;35:2541-2619.

ehu278.

16. McLeod SL, Iansavichene A, Cheskes S. Remote Ischemic Preconditioning to Reduce Reperfusion Injury During Acute ST-Segment-Elevation Myocardial Infarction: A Systematic Review and Meta-Analysis.J Am Heart Assoc. 2017;6:e005522. doi: 10.1161/JAHA.117.005522.

17. Ibanez B, James S, Agewall S, et al. 2017 ESC Guidelines for the management of acute myocardial infarction in patients presenting with ST-segment elevation. Eur Heart J. 2017. doi: 10.1093/eurheartj/ehx393. [Epub ahead of print]

18. Terkelsen CJ, Sorensen JT, Maeng M, et al. System delay and mortality among patients with STEMI treated with primary percutaneous coronary intervention. JAMA. 2010;304:763-771. doi: 10.1001/jama.2010.1139.

19. Fordyce C, Al-Khalidi H, Jollis J, et al. Association of Rapid Care Process Implementation on Reperfusion Times Across Multiple ST-Segment-Elevation Myocardial Infarction Networks. Circ Cardiovasc Interv. 2017;pii:e004061. doi:10.1161/CIRCINTERVENTIONS.

20. Stowens JC, Sonnad SS, Rosenbaum RA. Using EMS dispatch to trigger STEMI alerts decreases door-to-balloon times. West J Emerg Med. 2015;16:472-480. doi: 10.5811/ westjem.2015.4.24248.

21. Nallamothu BK, Normand SL, Wang $\mathrm{Y}$, et al. Relation between door-to-balloon times and mortality after primary percutaneous coronary intervention over time: a retrospective study. Lancet. 2015;385:1114-1122. ttp://dx.doi.org/10.1016/ S0140-6736(14)61932-2.

22. Welsh RC, Chang W, Goldstein P, et al. Time to treatment and the impact of a physician on prehospital management of acute ST elevation myocardial infarction: insights from the ASSENT-3 PLUS trial. Heart. 2005;91:1400-1406. doi: 10.1136/ hrt.2004.054510.

23. Henry TD, Sharkey SW, Burke MN, et al. A regional system to provide timely access to percutaneous coronary intervention for ST-elevation myocardial infarction. Circulation. 2007;116:721-728. doi: 10.1161/CIRCULATIONAHA.107.694141.

24. Benedek I, Gyongyosi M, Benedek T. A prospective regional registry of ST-elevation myocardial infarction in central Romania. Impact of the Stent for Life initiative recommendations on patient outcomes. Am Heart J. 2013;166:457-465. doi: 10.1016/j.ahj.2013.03.033.

25. Bajka B, Orzan M, Jakó B, Kovács I. Distance-related differences in critical times, protocol activation and mortality in a regional STEMI network. Journal of Cardiovascular Emergencies. 2016;2:122-128. doi: 10.1515/jce-2016-0019.

26. Orzan M, Benedek T, Bajka B, Pál K, Rat N, Benedek I. Impact of a preexisting STEMI network in improving STEMI diagnostic and treatment in the community after the introduction of a national program of interventional treatment in acute myocardial infarction. Journal of Cardiovascular Emergencies. 2015;1:23-28. doi: 10.1515/jce-2015-0004.

27. García-García C, Ribas N, Recasens LL, et al. In-hospital prognosis and long-term mortality of STEMI in a reperfusion network. "Head to head" analysis: invasive reperfusion vs. optimal medical therapy. BMC Cardiovasc Disord. 2017;17:139. doi: 10.1186/s12872-017-0574-6.

28. Cequier Á, Ariza-Solé A, Elola FJ, et al. Impact on Mortality of Different Network Systems in the Treatment of STsegment Elevation Acute Myocardial Infarction. The Spanish 
Experience. Rev Esp Cardiol (Engl Ed). 2017;70:155-161. doi: 10.1016/j.rec.2016.07.005.

29. Haller PM, Jäger B, Farhan S, et al. Impact of age on shortand long-term mortality of patients with ST-elevation myocardial infarction in the VIENNA STEMI network. Wien Klin Wochenschr. 2017. doi: 10.1007/s00508-017-1250-7. [Epub ahead of print]

30. Dharma S, Andriantoro H, Purnawan I, et al. Characteristics, treatment and in-hospital outcomes of patients with STEMI in a metropolitan area of a developing country: an initial report of the extended Jakarta Acute Coronary Syndrome registry. BMJ Open. 2016;6:e012193. doi: 10.1136/bmjopen-2016-012193.

31. Regueiro A, Fernández-Rodríguez D, et al. False Positive STEMI Activations in a Regional Network: Comprehensive Analysis and Clinical Impact. Results From the Catalonian Codi Infart Network. Rev Esp Cardiol (Engl Ed). 2017;pii:S1885-5857(17)30305-5. doi: 10.1016/j. rec.2017.06.001. [Epub ahead of print]

32. Kontos MC, Wang TY, Chen AY, et al. The effect of high-risk ST elevation myocardial infarction transfer patients on riskadjusted in-hospital mortality: A report from the American Heart Association Mission: Lifeline program. Am Heart J. 2016;180:74-81. doi: 10.1016/j.ahj.2016.07.010.

33. Park JJ, Yoon CH, Suh JW, et al. Reduction of Ischemic Time for Transferred STEMI Patients Using a Smartphone Social Network System. J Am Coll Cardiol. 2016;68:1490-1492. doi: 10.1016/j.jacc.2016.07.733.

34. Wong GC, van Diepen S, Ainsworth C, et al. Canadian Cardiovascular Society/Canadian Cardiovascular Critical Care Society/Canadian Association of Interventional Cardiology Position Statement on the Optimal Care of the Postarrest Patient. Can J Cardiol. 2017;33:1-16. doi: 10.1016/j. cjca.2016.10.021.

35. Bărcan A, Chițu M, Benedek E, et al. Predictors Of Mortality In Patients With ST-Segment Elevation Acute Myocardial Infarction And Resuscitated Out-Of-Hospital Cardiac Arrest. J Crit Care Med. 2016;2:22-30. doi: 10.1515/jccm-2016-0001.

36. Huang Y, He Q Yang LJ, Liu GJ, Jones A. Cardiopulmonary resuscitation (CPR) plus delayed defibrillation versus immediate defibrillation for out-of-hospital cardiac arrest. Cochrane Database Syst Rev. 2014;9:CDo09803. doi: 10.1002/14651858.CD009803.pub2.

37. Peek GJ. Community extracorporeal life support for cardiac arrest - when should it be used? Resuscitation. 2011;82:1117. doi: 10.1016/j.resuscitation.2011.06.006.

38. Strapazzon G, Plankensteiner J, Mair P, et al. Prehospital management and outcome of avalanche patients with out-ofhospital cardiac arrest: a retrospective study in Tyrol, Austria. Eur J Emerg Med. 2016. doi: 10.1097/MEJ.0000000000000390. [Epub ahead of print].

39. Hwang WS, Park JS, Kim SJ, Hong YS, Moon SW, Lee SW. A system-wide approach from the community to the hospital for improving neurologic outcomes in out-of-hospital cardiac arrest patients. Eur J Emerg Med. 2017;24:87-95. doi: 10.1097/ MEJ.0000000000000313.

40. Grunau B, Reynolds J, Scheuermeyer F, et al. Relationship between Time-to-ROSC and Survival in Out-of-hospital Cardiac Arrest ECPR Candidates: When is the Best Time to Consider Transport to Hospital? Prehosp Emerg Care. 2016;20:615-622. doi: 10.3109/10903127.2016.1149652.
41. Spangenberg T, Meincke F, Brooks S, et al. "Shock and Go?" extracorporeal cardio-pulmonary resuscitation in the goldenhour of ROSC. Catheter Cardiovasc Interv. 2016;88:691-696. doi: 10.1002/ccd.26616.

42. Johnson NJ, Acker M, Hsu CH, et al. Extracorporeal life support as rescue strategy for out-of-hospital and emergency department cardiac arrest. Resuscitation. 2014;85:1527-1532. doi: 10.1016/j.resuscitation.2014.08.028.

43. Grunau B, Scheuermeyer FX, Stub D, et al. Potential Candidates for a Structured Canadian ECPR Program for Out-of-Hospital Cardiac Arrest. CJEM. 2016:1-8. doi: 10.1017/cem.2016.8.

44. Ha TS, Yang JH, Cho YH, et al. Clinical outcomes after rescue extracorporeal cardiopulmonary resuscitation for out-ofhospital cardiac arrest. Emerg Med J. 2017;34:107-111. doi: 10.1136/emermed-2015-204817.

45. Sharma AS, Pijls RW, Weerwind PW, et al. Out-of-hospital cardiac arrest: the prospect of E-CPR in the Maastricht region. Neth Heart J. 2016;24:120-126. doi: 10.1007/s12471-0150782- 6.

46. Avalli L, Mauri T, Citerio G, et al. New treatment bundles improve survival in out-of-hospital cardiac arrest patients: a historical comparison. Resuscitation. 2014;85:1240-1244. doi: 10.1016/j.resuscitation.2014.06.014.

47. Leick J, Liebetrau C, Szardien S, et al. Door-to-implantation time of extracorporeal life support systems predicts mortality in patients with out-of-hospital cardiac arrest._Clin Res Cardiol. 2013;102:661-669. doi: 10.1007/s00392-013-0580-3.

48. Sarzyńska-Długosz I, Skowrońska M, Członkowska A. Organization of acute stroke services in Poland - Polish Stroke Unit Network development. Neurol Neurochir Pol. 2013;47:37.

49. Rymer MM, Thrutchley DE. Stroke Team at the Mid America Brain and Stroke Institute. Organizing regional networks to increase acute stroke intervention. Neurol Res. 2005;27:9-16. doi: 10.1179/016164105X25315.

50. Muengtaweepongsa S, Dharmasaroja P, Kummark U. Outcomes of intravenous thrombolytic therapy for acute ischemic stroke with an integrated acute stroke referral network: initial experience of a community-based hospital in a developing country. J Stroke Cerebrovasc Dis. 2012;21:42-46. doi: 10.1016/j.jstrokecerebrovasdis.2010.03.017.

51. Widimsky P, Hopkins LN. Catheter-based interventions for acute ischaemic stroke. Eur Heart J. 2016;37:3081-3089. doi:10.1093/eurheartj/ehv521.

52. Alonso de Leciñana-Cases M, Gil-Núñez A, Díez-Tejedor E. Relevance of stroke code, stroke unit and stroke networks in organization of acute stroke care - the Madrid acute stroke care program.

53. Leys D, Ringelstein EB, Kaste M, et al. The main components of stroke unit care: results of a European expert survey. Cerebrovasc Dis. 2007;23:344-352. doi: 10.1159/000099133.

54. Fuentes B, Díez-Tejedor E. Stroke units: many questions, some answers. Int J Stroke. 2009;4:28-37. doi: 10.1111/j.17474949.2009.00244.X.

55. Berkhemer OA, Fransen PS, Beumer D, et al. the MR CLEAN Investigators. A randomized trial of intraarterial treatment for acute ischemic stroke. N Engl J Med. 2015;372:11-20. doi: 10.1056/NEJMoa1411587.

56. Campbell BC, Mitchell PJ, Kleinig TJ, et al. Endovascular therapy for ischemic stroke with perfusion-imaging selection. $\mathrm{N} \mathrm{Engl} \mathrm{J}$ Med. 2015;372:1009-1018. doi: 10.1056/NEJMoa1414792. 
57. Saver JL, Goyal M, Bonafe A, et al. Stent-retriever thrombectomy after intravenous t-PA vs. t-PA alone in stroke. N Engl J Med. 2015;372:2285-2295. doi: 10.1056/ NEJMoa1415061.

58. Saver JL, Goyal M, Bonafe A, et al. Solitaire ${ }^{\mathrm{TM}}$ with the Intention for Thrombectomy as Primary Endovascular Treatment for Acute Ischemic Stroke (SWIFT PRIME) trial: protocol for a randomized, controlled, multicenter study comparing the Solitaire revascularization device with IV tPA with IV tPA alone in acute ischemic stroke. Int J Stroke. 2015;10:439-448. doi: 10.1111/ijs.12459.

59. Peisker T, Koznar B, Stetkarova I, Widimsky P. Acute stroke therapy: A review. Trends Cardiovasc Med. 2017;27:59-66. doi: 10.1016/j.tcm.2016.06.009.

60. Bellon RJ, Putman CM, Budzik RF, Pergolizzi RS, Reinking GF, Norbash AM. Rheolytic thrombectomy of the occluded internal carotid artery in the setting of acute ischemic stroke. Am J Neuroradiol. 2001;22:526-530.

61. Abelson M, Roos J, Rymer M. Mechanical thromboembolectomy in acute ischaemic stroke: a local experience. Cardiovasc J Afr. 2008;19:204-207.

62. DeVries JT, White CJ, Collins TJ, et al. Acute stroke intervention by interventional cardiologists. Catheter Cardiovasc Interv. 2009;73:692-8. doi: 10.1002/ccd.21927.

63. Hopkins N. Management of Acute Stroke by Cardiologists. Interventional Cardiology Review. 2011;6:86-88. http:// dx.doi.org/10.15420/icr.2011.6.1.86.

64. Abelson M, Roos J. Mechanical embolectomy for large vessel ischemic strokes: a cardiologist's experience. Catheter Cardiovasc Interv. 2010;76:309-315. doi: 10.1002/ccd.22621.

65. Heuser RR. We are ready, willing, and able: the interventional cardiology community: but we have two hands tied behind our back. Catheter Cardiovasc Interv. 2009;73:699-700. doi: 10.1002/ccd.22037.

66. Lanzer P, Camm J, Widimský P. Stroke in cardiovascular interventions. Eur Heart J. 2017;38:1278-1280. doi: 10.1093/ eurheartj/ehx193.

67. Lanzer P, Haude M, Widimsky P. Stroke management by cardiologists. Eur Heart J. 2017;38:2389-2390. doi: 10.1093/ eurheartj/ehx411.

68. Widimsky P, Koznar B, Peisker T, et al. Feasibility and safety of direct catheter-based thrombectomy in the treatment of acute ischaemic stroke. Cooperation among cardiologists, neurologists and radiologists. Prospective registry PRAGUE-16. EuroIntervention. 2017;13:131-136. doi: 10.4244/ EIJ-D-16-00979.

69. Froehler MT, Saver JL, Zaidat OO, et al. Interhospital Transfer Prior to Thrombectomy is Associated with Delayed Treatment and Worse Outcome in the STRATIS Registry. Circulation. 2017;pii:CIRCULATIONAHA.117.028920. doi: 10.1161/ CIRCULATIONAHA.117.028920. [Epub ahead of print]

70. Mueller-Kronast NH, Zaidat OO, et al. Systematic Evaluation of Patients Treated With Neurothrombectomy Devices for Acute Ischemic Stroke: Primary Results of the STRATIS Registry. Stroke. 2017;48:2760-2768. doi: 10.1161/ STROKEAHA.117.016456.
71. Switzer JA, Demaerschalk BM, Xie J, Fan L, Villa KF, Wu EQ. Cost-effectiveness of hub-and-spoke telestroke networks for the management of acute ischemic stroke from the hospitals' perspectives. Circ Cardiovasc Qual Outcomes. 2013;6:18-26. doi: 10.1161/CIRCOUTCOMES.112.967125.

72. Demaerschalk BM, Switzer JA, Xie J, Fan L, Villa KF, Wu EQ. Cost utility of hub-and-spoke telestroke networks from societal perspective. Am J Manag Care. 2013;19:976-985.

73. Tatlisumak T, Soinila S, Kaste M. Telestroke networking offers multiple benefits beyond thrombolysis. Cerebrovasc Dis. 2009;27:21-27. doi: 10.1159/000213055.

74. Audebert $\mathrm{H}$. Telestroke: effective networking. Lancet Neurol. 2006;5:279-282. doi: 10.1016/S1474-4422(06)70378-7.

75. Müller-Barna P, Schwamm LH, Haberl RL. Telestroke increases use of acute stroke therapy. Curr Opin Neurol. 2012;25:5-10. doi: 10.1097/WCO.0b013e32834d5fe4.

76. Zerna C, Siepmann T, Barlinn K, et al. Association of time on outcome after intravenous thrombolysis in the elderly in a telestroke network. J Telemed Telecare. 2016;22:18-24. doi: 10.1177/1357633X15585241.

77. Zanaty M, Chalouhi N, Starke RM, et al. Epidemiology of a large telestroke cohort in the Delaware valley. Clin Neurol Neurosurg. 2014;125:143-147. doi: 10.1016/j.clineuro.2014.06.006.

78. Sanders KA, Patel R, Kiely JM, Gwynn MW, Johnston LH. Improving Telestroke Treatment Times in an Expanding Network of Hospitals. J Stroke Cerebrovasc Dis. 2016;25:288291. doi: 10.1016/j.jstrokecerebrovasdis.2015.09.030.

79. Kepplinger J, Barlinn K, Deckert S, Scheibe M, Bodechtel U, Schmitt J. Safety and efficacy of thrombolysis in telestroke: A systematic review and meta-analysis. Neurology. 2016;87:1344-1351. doi: 10.1212/WNL.0000000000003148.

80. Pervez MA, Silva G, Masrur S, et al. Remote supervision of IVtPA for acute ischemic stroke by telemedicine or telephone before transfer to a regional stroke center is feasible and safe. Stroke. 2010;41:e18-e24. doi: 10.1161/STROKEAHA.109.560169.

81. Heffner DL, Thirumala PD, Pokharna P, Chang YF, Wechsler L. Outcomes of Spoke-Retained Telestroke Patients Versus HubTreated Patients After Intravenous Thrombolysis: Telestroke Patient Outcomes After Thrombolysis. Stroke. 2015;46:31613167. doi: 10.1161/STROKEAHA.115.009980.

82. Nardetto L, Giometto B, Moretto G, Mantoan D, Saia M. Huband-spoke stroke network in the Veneto region: a retrospective study investigating the effectiveness of the stroke pathway and trends over time. Neurol Sci. 2017. doi: 10.1007/s10072017-3118-z. [Epub ahead of print]

83. Chalouhi N, Dressler JA, Kunkel ES, et al. Intravenous tissue plasminogen activator administration in community hospitals facilitated by telestroke service. Neurosurgery. 2013;73:667771. doi: 10.1227/NEU.0000000000000073.

84. Klingner CM, Brodoehl S, Funck L, et al. Transfer of Patients in a Telestroke Network: What Are the Relevant Factors for Making This Decision? Telemed J E Health. 2017. doi: 10.1089/ tmj.2017.0087. [Epub ahead of print]

85. Ranta A, Lanford J, Busch S, et al. Impact and implementation of a sustainable regional telestroke network. Intern Med J. 2017. doi: 10.1111/imj.13557. [Epub ahead of print] 